INDEPENDENT JOURNAL OF MANAGEMENT \& PRODUCTION (IJM\&P)

http://www.ijmp.jor.br V. 11, n. 5, Special Edition IFLOG 2019 -September 2020 ISSN: 2236-269X

DOI: 10.14807/ijmp.v11i5.1257

\title{
CHALLENGES TO USE AN INTERDISCIPLINARY TASK IN LOGISTICS AND ENGLISH TEACHING: AN ANALYSIS OF A PERFORMANCE TEST
}

Eliana Kobayashi

Federal Institute of Education, Science and Technology of São Paulo, Brazil E-mail: likobayashi@ifsp.edu.br

David Eugênio Angelo Lima Federal Institute of Education, Science and Technology of São Paulo, Brazil E-mail: professordavid.associados@hotmail.com

Adriano Maniçoba Silva Federal Institute of Education, Science and Technology of São Paulo, Brazil E-mail: adrianoms@ifsp.edu.br

Submission: $1 / 27 / 2020$ Accept: 2/22/2020

\section{ABSTRACT}

In language performance assessment it is assumed that the best way to assess one's proficiency is to make her/him show such proficiency in a direct way in a situation close to the reality. Such view contrasts with knowledge testing which assesses language in an indirect way. This research objective is to discuss the development and application of an interdisciplinary task connecting two school subjects English Language and Logistics - in a performance language test, investigating the correlation between these two subjects' scores. This study uses qualitative method in order to build the test task and criteria and quantitative one to analyze the test scores. The research was developed in a public educational institution located in São Paulo metropolitan region and the results show that there is no correlation of the mean score between English language and Logistics subjects and students face more difficulties in using English than approaching the task topic content.

Keywords: English language teaching; Logistics; language performance assessment 
DOI: 10.14807/ijmp.v11i5.1257

\section{INTRODUCTION}

The English hegemony, which is present in $85 \%$ of international companies as one of the most used languages, and is also the main language in science and technology (GRADDOL, 2000), contributes to the argument that educational institutions roles should cover the development of the language skills of its students. In addition, companies that seek professionals in the market use specific assessment tools to analyze the English proficiency level of their applicants in recruitment processes (KOBAYASHI, 2010).

Specifically in Management and Business area, Logistics Technology is the second course more offered, representing a total of more than $22 \%$ of the courses in the area, including baccalaureate ones. Due to its applicability in international trade areas, Logistics professionals are supposed to know how to communicate in English in order to meet the market demands. Thus the language should be effectively taught, tested and assessed.

Language testing is used to many purposes and among them to identify how far students have achieved the objectives of a course and also to diagnose their strengths and weakness (HUGHES, 1989). Having said it, teachers play an important role as they are usually the ones who build the achievement tests. Building a fair and valid test can be seen as a challenge especially considering the specificities of a language uses. However, one of the most relevant aspects when building a test should be its similarity to the authentic language use.

One of the ways to approach such use when building achievement tests is through interdisciplinary tasks which allow more integration between English language and other subjects. One of the most important point is to create situations in which students can show their language skills in situations close to real life.

This research was developed in a class of a technical degree course in Business integrated to high school curriculum at a public educational institution located in São Paulo metropolitan area. Such course leads to two diplomas: a high school one and a technical degree course in Business diploma. The objective was to build and apply an English language achievement test based on a Logistics subject task and investigate the correlation between these two subjects' scores. Although it is known that teaching and testing are two related activities and they have to be planned and developed together, this article focusses on describing the latter.

The students must take around eighteen subjects every semester in the three year technical course in Business integrated to high school curriculum. Among them there are 
DOI: 10.14807/ijmp.v11i5.1257

English language (mandatory subject in the three years of the course) and Logistics (mandatory subject in the second year of the course).

In English subject, students are expected to develop among communicative skills and strategies to express abilities, intentions, predictions, conditions and hypothetical situations, among several other topics. Logistics content is taught in Logistics and covers distribution channels, supply chain management, supplier management, packaging management. Concerning specifically Logistics field, by the end of the course, students are expected to be able to understand how the following areas work: retail and wholesale; integrated management between marketing and supply chain and physical and visual packaging.

The group who participated in this investigation was composed of 38 students aged from 15 to 16 years old and were attending the second year of the course. English language and Logistics subjects were each taught weekly in a 100 minute-lesson.

\section{LITERATURE REVIEW}

Testing is an activity which is required in several contexts and not only in academic settings. The main purpose is to check if the applicants are able to perform according to some established criteria and as a consequence the test results may impact their lives in different ways. Testing is a process which always involves consequences (STOBART, 2003).

In language testing there four types of tests, classified according to their purposes: proficiency tests, achievement tests, diagnostic tests and placement tests. As this research investigates how to build and score a test according to what is taught in two course subjects, the suitable test is the achievement one.

The definition of achievement tests, for HUGHES (1989) are those "directly related to language courses, their purpose being to establish how successful individual students, groups of students, or the courses themselves have been in achieving objectives". Hughes also emphasized that tests should be based on objectives as it can provide accurate information about individual and group achievement.

The main purpose of studying a language is to become able to communicate using it. Thus English in academic settings should be taught and tested as a specific purpose language. The connection between English language and Logistics content is a key aspect in this research and for this reason English language subject teacher researcher and Logistics researcher teachers worked in this collaborative study. Douglas (2000) emphasizes such relation in the definition of specific purpose language test. 


\begin{abstract}
A specific purpose language test is one in which test content and methods are derived from an analysis of a specific purpose target language use situation, so that test tasks and content are authentically representative of tasks in the target situation, allowing for an interaction between the test taker's language ability and specific purpose content knowledge, on the one hand, and the test tasks on the other. Such a test allows us to make inferences about a test taker's capacity to use language in the specific purpose domain (DOUGLAS, 2000, p. 19).
\end{abstract}

The relation between target language and content was also discussed by Bachman and Palmer (1996) who presented three possibilities for what they called the relationship between language ability and topical knowledge. In the first one, the inferences should be only about language knowledge when test takers vary widely in topical knowledge. On the other hand, in situations where such variety is considered minimum, language and topical knowledges should be tested. The last possibility would be a separation between language construct and topical knowledge construct in cases where test developers and scores users are uncertain about the strength of the test taker's topical knowledge.

The importance of topical knowledge has been emphasized for a long time and by other authors like Jones (1979, p. 51) claimed: "it is impossible for a language test to predict taskoriented proficiency unless it includes or approximates actual samples of the tasks". Having said it, this work relies on the alignment between English language subject and Logistics (Logistics) subject in an interdisciplinary testing task.

Besides purpose, tests differ in terms of methods. McNamara (2000) distinguishes paper-and-pencil language tests from performance tests. The former is related to more traditional and familiar examination paper which usually separates components of language knowledge like grammar, vocabulary or skills like reading, listening etc. The author also points out that this kind of test usually has a fixed response format whose most important type is the multiple choice one.

On the other hand, performance test aims to assess language skills in an act of communication in a situation close to real-life context as described by McNamara (2000) "(...) most commonly tests of speaking and writing, in which a more or less extended sample of speech or writing is elicited from the test taker and judged by one or more trained raters using an agreed rating procedure".

According to McNamara (2000), testing is about making inferences since a test provides indicators of how a person would probably perform in real life. For this reason, the author 
ISSN: 2236-269X

DOI: 10.14807/ijmp.v11i5.1257

claims that "understanding testing involves recognizing a distinction between the criterion (relevant communicative behavior in the target situation" and the test.

Table 1: Test and criterion

\begin{tabular}{|c|c|c|}
\hline Test & \multirow{3}{*}{$\begin{array}{l}\text { Characterization of the } \longleftarrow \\
\text { essential features of the criterion } \\
\text { influences the design of the test } \\
\longleftarrow \quad \text { Inferences about }\end{array}$} & Criterion \\
\hline $\begin{array}{l}\text { A performance or series of } \\
\text { performances, simulating } \\
\text { representing or sampled from } \\
\text { the criterion. }\end{array}$ & & $\begin{array}{l}\text { A series of performances } \\
\text { subsequent to the test; the } \\
\text { target }\end{array}$ \\
\hline (observed) & & (unobservable) \\
\hline
\end{tabular}

The figure shows that the criterion consists of the target performance expected to happen in real life situations and which the applicants are supposed to be able to perform. For this reason, it is not possible to be observed in the test. On the other hand, the test is a performance that simulates the ones specified by the criterion.

McNamara (2000, p.9) claims that "although this criterion behavior, as relevant to the appropriate communicative role (as nurse, for example, or student), is the real object of interest, it cannot be accounted for as such by the test". Thus, the criterion behavior is elusive because it cannot be actually observed. The author points out testers must check the empirical evidence for their position when assessing candidates, thus it is necessary to analyze candidates in the light of their actual performance on test tasks.

For these reasons, in this study we aim to balance the topical knowledge and the English language knowledge according to the objectives of the subjects (English and Logistics) building a test which reflects the proficiency level and content expected from the participants.

Interdisciplinary testing in this study involves collaboration to analyze students' performance so test content and method have to be set in the test specifications which work as a blueprint for its construction.

In terms of oral testing task, this research follows the suggestions presented by Hughes (1989) who makes use of the framework introduced by the Royal Society of Arts (RSA). Their oral test specifications cover: Operations, Types of texts, Addressees, and Topics.

Table 2: Oral test specifications

\begin{tabular}{ll}
\hline Operations & $\begin{array}{l}\text { The operation is to take part in oral interaction which may involve the following } \\
\text { language functions: }\end{array}$ \\
\hline Expressing: & $\begin{array}{l}\text { Thanks, requirements, opinions, comment, attitude, confirmation apology, want/need, } \\
\text { information, complaints, reasons/justifications. }\end{array}$ \\
\hline Narrating: & Sequence of events \\
\hline Eliciting: & Information, directions, service, clarification, help, permission (all areas above) \\
\hline
\end{tabular}


ISSN: 2236-269X

DOI: 10.14807/ijmp.v11i5.1257

\begin{tabular}{ll}
\hline Directing: & Ordering, instructions (how to), persuading, advising, warning \\
\hline Reporting: & Description, comment, decisions \\
\hline Text types & $\begin{array}{l}\text { Dialogue and multi-participant interactions normally of face-to-face nature but } \\
\text { telephone conversations not excluded. }\end{array}$ \\
\hline $\begin{array}{l}\text { Addressees } \\
\text { and topics }\end{array}$ & Not specified except as under "Topics for writing". \\
\hline
\end{tabular}

Source: Hughes (1989, p. 101)

On the other hand, it is also necessary to combine such content elements with the expected proficiency level. There are frameworks and guidelines worldwide used which describe what candidate should be able to do in different levels such as ACTFL Guidelines and the Common European Framework for Language. In this research, the latter is used in order to set the proficiency ratings. Such level is also specified in the course program as an objective to be reached along the year.

Specifically concerning the oral skill, the CEF A2 level establishes the expected "can do" for speaking divided in spoken interaction and spoken production.

Table 3: Spoken interaction and spoken production

\begin{tabular}{|l|l|}
\hline $\begin{array}{l}\text { Spoken } \\
\text { interaction }\end{array}$ & $\begin{array}{l}\text { I can communicate in simple and routine tasks requiring a simple } \\
\text { and direct exchange of information on familiar topics and activities. } \\
\text { I can handle very short social exchanges, even though I can't } \\
\text { usually understand enough to keep the conversation going myself. }\end{array}$ \\
\hline $\begin{array}{l}\text { Spoken } \\
\text { production }\end{array}$ & $\begin{array}{l}\text { I can use a series of phrases and sentences to describe in simple } \\
\text { terms my family and other people living conditions, my educational } \\
\text { background and my present or most recent job. }\end{array}$ \\
\hline
\end{tabular}

These research participants are expected to be moving up from this level to B1. On the other hand, as the task purposed in this research focusses on a specific topical knowledge reflecting a particular domain, CEF level description would not match the target level. Thus, although many aspects were kept, others have to be included due to the target language specificities.

\section{METHODOLOGY}

This research is a qualitative work as it aims to develop an investigation in depth to better understand how a phenomena works in the context. Shank (2002, p.5) defines this kind of research as "a form of systematic empirical inquiry into meaning".

Yin (1984, p.23) claims it is "an empirical enquiry that investigates a contemporary phenomenon within its real-life context; when the boundaries between phenomenon and context are not clearly evident; and in which multiple sources of evidence are used". 
DOI: 10.14807/ijmp.v11i5.1257

In this type of research, a very used technique is the triangulation since there are usually multiple sources of data (CRESWELL, 1998). According to Denzin (1978), there are four types of triangulation techniques: sources, methods, researchers and theories. The most used ones pointed by the authors were also applied in this investigation the sources and methods. The objective of using different sources of data and methods is to decrease the bias of one technique to compensate with another (LINCOLN; GUBA, 1985).

\section{1. $\quad$ Setting and participants}

This study was developed in a public educational institution located in São Paulo metropolitan area. In order to study there, students must go through a selection process administered by the institution. There are usually more applicants than available places which makes entrance competitive.

The participants of this research, a total of 40 students, attend a technical degree course in business integrated with high school curriculum. The subjects including English language and Logistics subjects are taught and tested separately. In this investigation, these subjects' teachers, planned the classes, the tests and applied the oral test together but the lessons were delivered separately.

\subsection{The test task}

The task built for the test has two main objectives: analyze the expected English level (CEF A2) and the topical knowledge in Logistics. The main skill to be assessed is the speaking in a group (four students) presentation. Participants are scored individually based on the criteria shared with the students by both researchers.

\section{Table 4: Spoken production description}

\begin{tabular}{|l|l|}
\hline Spoken & I can describe the company I work for: its mission and objectives. \\
I can describe the service or products offered by the company I work for. \\
I can communicate the actions that could be taken in a Logistics area to improve \\
the service or products of the company I work for.
\end{tabular}

\subsection{Task instructions}

\section{Group activity}

You are the managers of your company and have to work together to raise the productivity to $15 \%$, focusing on distribution channel, retail and wholesale activities.

Prepare an oral presentation to the board of directors explaining your proposal. The use of slides and visual communication such as banners, catalogues etc can help your work. Each of you has to deliver part of the presentation. 
ISSN: $2236-269 X$

DOI: 10.14807/ijmp.v11i5.1257

Step 1: Describe your company

Step 2: Select the problems to be solved

Step 3: Focus on the distribution channel, retail and wholesale

Step 4: Raise the possibilities and expected results (hypothesis)

The chart below can help you develop your ideas.

\begin{tabular}{|l|l|l|l|}
\hline Action Plan & Current scenario & What woud happen IF... & Predicted results \\
\hline $\begin{array}{l}\text { Distribution } \\
\text { channel }\end{array}$ & Suppliers delay & $\begin{array}{l}\text { Changed the raw material } \\
\text { suppliers }\end{array}$ & $\begin{array}{l}\text { Improve delivery and } \\
\text { finished product quality }\end{array}$ \\
\hline
\end{tabular}

\subsection{The test criteria}

The performance assessment task designed for this study was used as an achievement test in order to collect evidence to analyze learning progress for both subjects. The assessment criteria were also built after the task design.

Table 5: Assessment criteria - Logistics subject and English Language subjects Logistics (topical knowledge) assessment criteria

\begin{tabular}{|l|l|l|}
\hline Criteria & Description & Scale \\
\hline Distribution channel & Describe supply chain and marketing tool used & $0-20$ \\
\hline Retail & Describe sale, primary and secondary packaging & $0-30$ \\
\hline Wholesale & Describe batches, transport packaging & $0-30$ \\
\hline Service level & Describe customers' satisfaction and how it will be measured. & $0-20$ \\
\hline
\end{tabular}

English Language criteria

\begin{tabular}{|l|l|l|}
\hline Criteria & Description & Scale \\
\hline Task achievement & Accomplish what was proposed in the task & $0-25$ \\
\hline Content & Cover the specified aspects & $0-25$ \\
\hline Grammar and vocabulary & Use forms and specific lexis to the proposed business situation & $0-25$ \\
\hline Pronunciation & Pronounce words intelligibly & $0-25$ \\
\hline
\end{tabular}

\section{RESULTS}

In Logistics subject, the participants of this study have worked on creating a fictional company covering aspects like: name, product, mission, objectives, target, market and so on. Students had also learned topics related to Logistics: distribution channel, supply chain, retail, wholesale and how to measure the company service satisfaction.

Concerning English language, students had already learned how to describe current situations and past events, and express hypothetical situation and advice. Thus, the task designed in this interdisciplinary work aims to join what participants have studied allowing them to connect the acquired knowledge and skills which have been developed. For this reason, the task instructions were set specifying such connection and students are expected to work in the same group that developed a company in Logistics subject. 
DOI: 10.14807/ijmp.v11i5.1257

The Logistics subject teacher assessed the topical knowledge based on the students' delivery and also on a handout summarizing the presentation in Portuguese. An oral presentation even with visual resources but only in English could hinder communication for those who are not used to assessing topical knowledge in situations where language errors, slips and cohesion usually happen.

First of all, to better understand how students performed in each subject (English language and Logistics) the mean scores were analyzed separately. In addition, the paired t-test was used to check the correlation between the two scores samples.

The histogram of English shows that most of the students got scores between 6 and 6.5 and the highest one was 8.5. However all students were approved since the passing score is 6 .

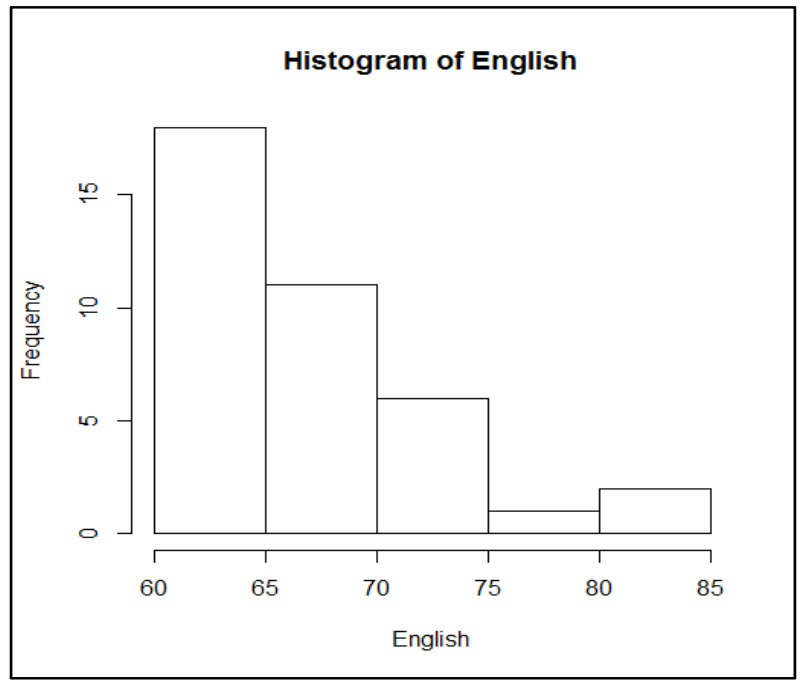

Chart 1: Histogram of English

The histograms of English scores (Chart 1) and Logistics ones (Chart 2) show that scores had different distributions according to the observed frequencies. Table 6 supports such difference showing the data descriptive measures which indicate differences between parameters like mean, median, standard deviation, minimum, maximum and quartiles. It is possible to notice that Logistics score was higher than the English score.

On the other hand, in Logistics subject the results were virtually the opposite as most of the students achieved the highest scores, between 9 and 10 . However there were also students who were not approved, with scores below 6 . 


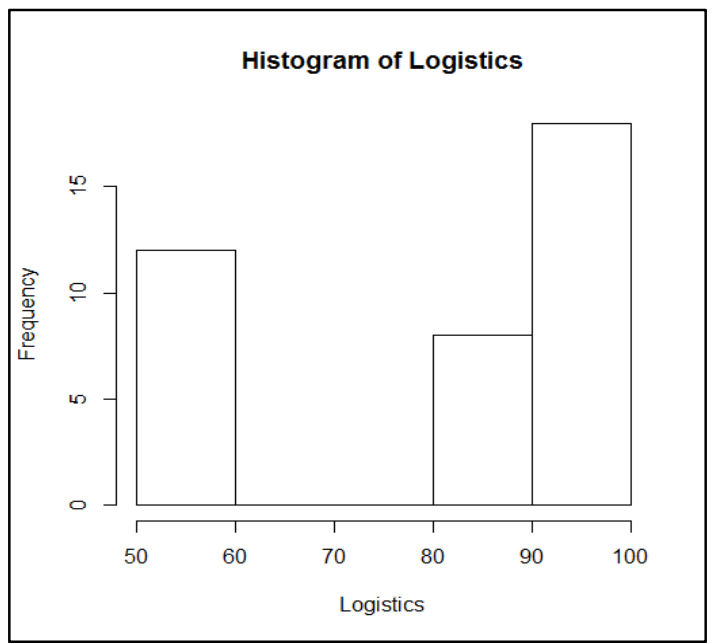

Chart 2: Historigram of Logistics

Thus as the descriptive statistics below show the scores given by the English teacher are lower than the Logistics one. As a consequence there's a weak negative correlation of 0.2917 between the two variables with significance level of 10\%. (Table 6, Chart 3 and Table 7)

Table 6: Descriptive statistics

\begin{tabular}{|l|l|l|}
\hline & English & Logistics \\
\hline Mean & 67.76 & 82.10 \\
\hline Standard deviation & 7.23 & 17.88 \\
\hline Median & 70 & 90 \\
\hline Maximum & 85 & 100 \\
\hline Minimum & 60 & 50 \\
\hline $1^{\text {st }}$ quartile & 60 & 60 \\
\hline $3^{\text {rd }}$ quartile & 70 & 95 \\
\hline
\end{tabular}

The correlation analysis between English score and Logistics score (Chart 3) show a weak negative correlation between the variables.

Chart 3: Correlation between English and Logistics scores

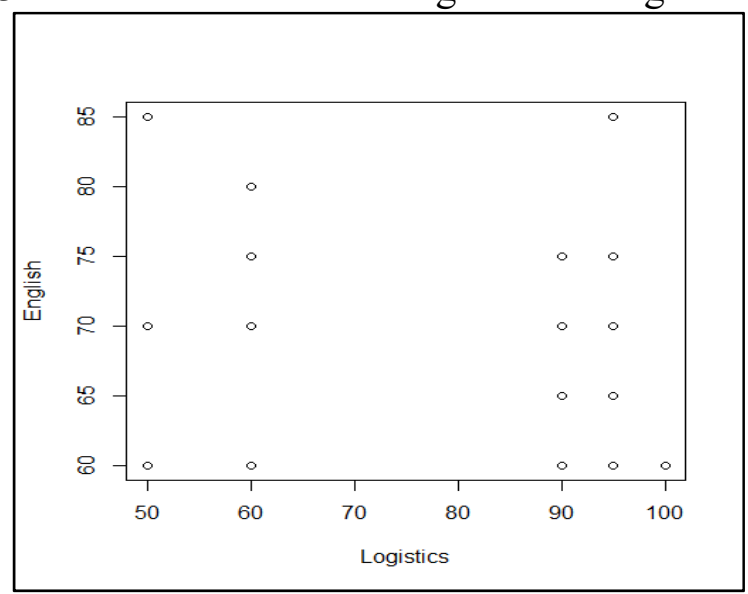

In order to check the difference between the scores, the Pearson test correlation was used and the results strengthened the hypothesis of difference. 
Table 7: Pearson's product-moment correlation

\begin{tabular}{|l|l|}
\hline$t$ test & -1.83 \\
\hline Degrees of freedom & 36 \\
\hline$p$-value & 0.0754 \\
\hline Correlation coefficient & -0.2917 \\
\hline
\end{tabular}

Therefore, comparing the two samples, the hypothesis that the two means are equal is rejected.

Table 8: Results of paired t-test

\begin{tabular}{|l|l|}
\hline Value of $\mathrm{t}$ & 4.17 \\
\hline $\mathrm{p}$-value & $<0.01$ \\
\hline Degrees of freedom & 37 \\
\hline
\end{tabular}

\section{DISCUSSION}

The achievement test task applied in this investigation was built aligning English language and Logistics subject in an interdisciplinary attempt to assess language as it is expected to be performed in a real life situation. The criteria were described by both teachers in order to assure what students had to present in the designed performance test (MCNAMARA, 2000) as well as the score scales.

This study emphasizes the importance of performance tests to increase the students' ability to use the language and more specifically the speaking skill which is usually neglected in Brazilian regular schools. In addition, performance tests are especially relevant to technical course students who usually aim to find a job soon after getting the diploma as they can better prepare students for professional situations like job selections tests which involve several other specific knowledge apart from English.

The construction and application of this test task allowed students to better connect two subjects that may be taught separately but can have much in common as many other subjects. English for Specific Purposes in particular have special connection with technical subjects and should for this reason be taught and tested in an interdisciplinary way so the language specificities could be better understood (DOUGLAS, 2000). Thus it is paramount to build activities which can raise such awareness in students and teachers as well as.

The score results indicate that students face considerable more difficulties in dealing with English than with the Logistics subject since both subject scores could not be correlated and the language ones were rather lower on average. Although people in general fear public speaking and the situation may be hypothetically worse in a foreign language, the scores show that the students knew what to talk in the context but they faced obstacles to express it. 
DOI: 10.14807/ijmp.v11i5.1257

As a first time experience for teachers and students, the fact that participants were able to carry out the whole task may be seem as a positive outcome. This can increase their ability to deal with other performance tests in the future. On the other hand, there is room for improvement in language use so they can better know how to do it.

\section{CONCLUSION}

This paper presents an interdisciplinary task used in performance language test. Aspects like test task construction, its objectives, expected "can do" in the language, expected topical knowledge content, criteria descriptions and scoring were discussed. Results show that there is no correlation between English language and Logistics subjects mean scores. Besides, students had on average lower scores in English, the highest score (10) was given in Logistics but also the lowest one (5). The results indicate that there is room for improvement in language use.

This study result can contribute to reflections on how teachers can build achievement tests that can be more meaningful and close to real situations considering the wide range of subjects that students take every term. On the other hand, one limitation of this research is the low number of participants and the fact that they were all from the same class. For this reason, it would be important to develop further investigations involving more students and classes in order to identify possible similarities or differences.

\section{REFERENCES}

BACHMAN, L.; PALMER, A. S. (1996) The construct validation of some components of communicative proficiency. TESOL Quarterly, v. 16, n. 4, p. 449-65.

Common European (2001) Framework of Reference for Languages: Learning, Teaching, Assessment Cambridge University Press: Cambridge.

CRESWELL, J. W. (1998) Qualitative Inquiry and Research Design: Choosing Among Five Traditions. London: SAGE Publications Ltd

DENZIN, N. K. (1978) Sociological methods. Nova York: McGraw-Hill.

DENZIN, N.; LINCOLN, Y. (2006) O planejamento da pesquisa qualitativa: teorias e práticas. Tradução Sandra Regina. Netz. Porto Alegre: Armed.

DOUGLAS, D. (2000) Assessing Language for Specific Purpose. Cambridge: Cambridge University Press.

GRADDOL, D. (2000) The future of English? The British Council.

HUGHES, A. (1989) Testing for language teachers. Cambridge: Cambridge University Press. 
JONES, R. L. (1979) Performance testing of second language proficiency. In Briere E.J. and Hinofotis F.B. (eds) Concepts in language testing: some recent studies, TESOL, Washington DC p. 50-7.

KOBAYASHI, E. (2010) Processos avaliativos em língua estrangeira (inglês): Um estudo de caso em contexto empresarial. Dissertação (Mestrado em Linguística Aplicada) - Instituto de Estudos da Linguagem, Universidade Estadual de Campinas, Campinas.

LINCOLN, Y. S.; GUBA, E. G. (1985) Naturalistic Inquiry. Beverly Hills: Sage.

MCNAMARA, T. (2000) Language Testing. Oxford: Oxford University Press.

Shank, G. (2002) Qualitative Research. A Personal Skills Aproach. New Jersey: Merril Prentice Hall.

STOBART, G. (2003) Alternative Assessment. In: KELLAGHAN, T.; STUFFLEBEAM, D. (eds). International Handbook of Educational Evaluation. Kluwer Academic Press, Dordrecht, Netherlands, p. 549-576, 2003.

YIN, R. K. (1984) Case study research: design and methods. California: Sage publications. 